\title{
Keberkesanan Penggunaan Kaedah Frog VLE Terhadap Pencapaian Matematik Sekolah Rendah
}

\author{
Effectiveness of VLE Frog Method on the Achievement of Mathematics in Primary \\ School
}

\author{
Theinmoli Munusamy ${ }^{1}$, Maizatul Hayati Mohamad Yatim² \\ ${ }^{1}$ Fakulti Seni, Komputeran dan Industri Kreatif, Universiti Pendidikan Sultan Idris; thein.moli@gmail.com \\ ${ }^{2}$ Fakulti Seni, Komputeran dan Industri Kreatif, Universiti Pendidikan Sultan Idris; maizatul@fskik.upsi.edu.my
}

\begin{abstract}
Abstrak
Kajian ini bertujuan untuk mengkaji keberkesanan kaedah Persekitaran Pembelajaran Maya Frog (Frog VLE) terhadap pencapaian Matematik pelajar Tahun Dua di Sekolah Jenis Kebangsaan Tamil Mahathma Gandhi Kalasalai. Frog VLE merupakan sistem pembelajaran maya secara Web yang digunakan sebagai sistem pengurusan pembelajaran di semua sekolah di Malaysia. Tiga objektif kajian iaitu mengukur keberkesanan penggunaan Frog VLE terhadap pencapaian Matematik, mengukur tahap kepuasan dan tahap kemahiran menggunakan Frog VLE dalam kalangan pelajar. Pendekatan penyelidikan kuantitatif dipilih melalui reka bentuk eksperimen. Tiga set instrumen digunakan iaitu soalan pengujian, soal selidik dan senarai semak kompetensi kemahiran. Seramai enam puluh orang pelajar dipilih menjadi menjadi sampel kajian. Dapatan kajian ini menunjukkan perbezaan pencapaian Matematik yang signifikan min antara pelajar yang mengikuti pembelajaran melalui Frog VLE berbanding pembelajaran secara tradisional. Tahap kepuasan penggunaan kaedah Frog VLE adalah tinggi dan tahap kemahiran penggunaan kaedah Frog VLE adalah sederhana Implikai kajian ini dapat dimanfaatkan oleh guru dan dijadikan panduan memperbaiki teknik pengajaran dan pembelajaran. Secara kesimpulannya, kaedah Frog VLE boleh digunakan untuk membantu pengajaran dan pembelajaran dalam meningkatkan pencapaian mata pelajaran Matematik dengan bimbingan guru.
\end{abstract}

Kata kunci: Frog VLE, pembelajaran maya, Matematik.

\section{Abstract}

This study aimed to investigate the effectiveness of Frog Virtual Learning Environment (Frog VLE) method in the achievement of Mathematics among year two children at Sekolah Jenis Kebangsaan Tamil Mahathma Gandhi Kalasalai. VLE Frog is a virtual learning system through Web which is used as a learning management system in all schools in Malaysia. The three objectives of this study are to measure the effectiveness of VLE Frog method in the achievement of Mathematics, to assess the stage of satisfaction and the skill level of using VLE Frog among students. A quantitative research approach using experimental design was chosen. Three sets of instruments used were the testing questions, questionnaire and skills competency checklist. Sixty students were chosen as a sample for this investigation. The finding shows a significant difference in the achievement of Mathematics among the students learning through VLE Frog compared to traditional approach. The satisfaction level of 
using VLE Frog is high and the level of skills in using VLE Frog were intermediate. The implications of this study can be beneficial to teachers and serve as a guide to improve teaching and learning techniques. In conclusion, VLE Frog method can be used for teaching and learning to enhance students' achievement in Mathematics with assistance from their teachers.

Keywords: VLE Frog, virtual meaning, Mathematics

\section{PENGENALAN}

Salah satu inisiatif Kementerian Pendidikan Malaysia (KPM) adalah melaksanakan Projek 1BestariNet ke semua sekolah untuk mengintegrasi Teknologi Maklumat dan Komunikasi (TMK) dalam pembelajaran harian. Projek 1BestariNet merupakan projek inisiatif KPM dengan kerjasama Frogasia (YTL Communication).

Menurut Norazilawati Abdullah (2013), Persekitaran Pembelajaran Maya (VLE) adalah satu kaedah penyelesaian bersepadu yang menjurus kepada pengajaran, pembelajaran, kolaborasi dan pengurusan pentadbiran boleh diakses di sekolah atau di mana-mana sahaja melalui capaian Internet. Bahan interaktif yang digunakan dalam Persekitaran Pembelajaran Maya (VLE) seperti forum, video dan kuiz dalam talian membantu pelajar untuk mengambil bahagian secara aktif dalam pembelajaran dan ini memberi kepuasan dan hasil yang positif kepada pelajar (Azrien \& Sariah, 2014).

Frog VLE ini telah memberi kesan kepada pembangunan komuniti dalam persekitaran sekolah. Menurut Nurul Farhana (2013), penyediaan platform Frog VLE kepada sekolah, guru, pelajar dan ibu bapa di sekolah seluruh Malaysia oleh Kementerian Pelajaran Malaysia (KPM) adalah satu langkah positif dalam menjadikan Malaysia setaraf dengan pendidikan negara maju lain. Aktiviti pembelajaran berpusatkan pelajar mampu memupuk nilai kreatif dan inovatif, bersikap tanggungjawab dan bekerjasama antara sesama pelajar di samping meningkatkan kemahiran kolaborasi di kalangan pelajar (Nurul Juzailah, 2013).

Selain itu, Frog VLE adalah satu platform yang menyokong pengajaran dan pembelajaran dan bertindak sebagai bilik darjah dalam talian dan ruang sosial bagi seluruh sekolah (Ida Norini, 2013). Strategi pengajaran yang baik dengan menggunakan laman pengajaran yang direka bentuk oleh guru di dalam Frog VLE ini menarik minat pelajar untuk faham dan belajar selain meningkatkan pengetahuan mereka (Shahfiezul \& Fariza, 2015). Menurut Siti Hashidah (2015), penggunaan kaedah Frog VLE yang interaktif dan berkonsepkan online dalam pembelajaran dipercayai dapat menarik minat golongan pelajar di mana jua pada bila-bila masa.

Selaras dengan perkembangan TMK dan Internet, penggunaan pelbagai sumber pendidikan secara menyeluruh dapat menarik dan memberi motivasi kepada pelajar yang kurang fokus dalam proses pengajaran dan pembelajaran. Dengan menggunakan pendekatan Frog VLE, pengajaran dan pembelajaran lebih menarik di mana pelajar dapat mengalami keadaan pembelajaran mereka sendiri menerusi projek yang dilaksanakan. Oleh itu, perancangan yang terperinci perlu dibuat bagi 
memastikan pelaksanaan sesuatu konsep itu dapat dilaksanakan dengan berkesan serta kepakaran dan keperluan sumber yang sesuai. Sehubungan itu, kajian ini dicuba untuk menghurai persoalan berkaitan keberkesanan penggunaan kaedah Frog VLE dalam peningkatan prestasi pelajar bagi mata pelajaran Matematik. Berikut adalah objektif yang menjadi asas dalam penyelidikan ini.

i. Mengukur keberkesanan penggunaan kaedah Frog VLE terhadap pencapaian mata pelajaran Matematik dalam kalangan pelajar Tahun 2;

ii. Mengukur tahap kepuasan menggunakan kaedah Frog VLE dalam kalangan pelajar Tahun 2; dan

iii. Mengukur tahap kemahiran menggunakan kaedah Frog VLE dalam kalangan pelajar Tahun 2

\section{PENYATAAN MASALAH}

Terdapat beberapa masalah yang sering dikaitkan dalam pengajaran mata pelajaran Matematik Tahun 2. Pertamanya, pelajar-pelajar tidak terlibat secara aktif ketika berada di dalam kelas. Menurut Ida Norini (2013), terdapat segelintir pelajar yang kurang memberi perhatian di dalam kelas. Di dalam kelas tradisional, suasana pembelajaran adalah berpusatkan guru. Di samping itu, bilangan pelajar yang ramai di dalam kelas menyebabkan wujudnya situasi di mana perhatian guru kurang dapat diberikan secara individu. Pengajaran dan pembelajaran hanya dijalankan secara formal iaitu di dalam bilik darjah. Sekiranya pelajar tidak faham di dalam kelas dan malu bertanya maka pelajar tersebut kekal tidak memahami isi pelajaran yang diajar. Seterusnya, masalah yang sering dikaitkan dengan mata pelajaran Matematik ialah kekurangan kemahiran dalam menyelesaikan soalan Matematik. Masalah kemerosotan mata pelajaran Matematik yang secara amnya semakin meningkat jelas dapat dilihat pada keputusan Ujian Penilaian Sekolah Rendah (UPSR), Peperiksaan Pentaksiran Tingkatan 3 (PT3) dan Sijil Pelajaran Malaysia (SPM) yang diumumkan setiap tahun, di mana mata pelajaran Matematik sentiasa menjadi mata pelajaran yang mempunyai peratus pencapaian yang amat merunsingkan (Johari Hassan \& Yeong Wai Chung, 2010).

\section{METODOLOGI}

Kajian ini menggunakan kaedah tinjauan dan kaedah eksperimen. Kaedah eksperimen digunakan untuk mengukur keberkesanan penggunaan kaedah Frog VLE terhadap pencapaian mata pelajaran Matematik Tahun 2 manakala kaedah tinjauan digunakan untuk mengukur tahap kepuasan dan kemahiran menggunakan kaedah Frog VLE dalam kalangan pelajar Tahun 2. Sepanjang pelaksanaan kajian yang dirancang, data dikumpul dan direkodkan. Setelah tempoh masa kajian dijalankan berakhir, refleksi dilakukan berdasarkan dapatan dan data yang dipungut. 


\section{Lokasi, Populasi dan Sampel Kajian}

Subjek bagi kajian ini adalah pelajar dari SJK (T) Mahathma Gandhi Kalasalai, Sungai Siput (U) Perak. Sampel kajian telah dipilih secara rawak untuk menjalankan eksperimen ini. Saiz sampel ialah 60 orang pelajar. Sebanyak 30 orang pelajar dipilih bagi kumpulan rawatan dan 30 orang pelajar bagi kumpulan kawalan masing-masing. Pelajar-pelajar yang terpilih sebagai subjek bagi kumpulan rawatan menjalani proses pembelajaran menggunakan kaedah Frog VLE manakala pelajar-pelajar yang terpilih sebagai subjek bagi kumpulan kawalan menjalani proses pembelajaran dengan menggunakan kaedah tradisional.

\section{Instrumen Kajian}

Penyelidik menggunakan beberapa instrumen iaitu soalan pengujian (ujian pra dan ujian pasca), soal selidik serta senarai semak kompetensi kemahiran dalam proses pungutan data.

\section{Soalan Pengujian}

Terdapat dua bentuk soalan pengujian iaitu ujian pra dan ujian pasca. Ia dilakukan untuk melihat perbandingan pencapaian pelajar di antara kumpulan yang menggunakan kaedah Frog VLE dengan kumpulan yang menggunakan kaedah tradisional bagi Matematik.

\section{Soal selidik Pelajar}

Borang soal selidik diberikan kepada pelajar dari kumpulan rawatan bagi menjawab item kepuasan yang disenaraikan dalam borang soal selidik. Soal selidik direka bentuk berdasarkan objektif kajian iaitu mengukur tahap kepuasan kaedah Frog VLE.

\section{Senarai Semak Kompetensi Kemahiran}

Beberapa kompetensi dalam senarai semak yang berkait dengan Frog VLE dinilai bagi pelajar dari kumpulan rawatan. Kemahiran setiap pelajar dalam kumpulan rawatan dinilai oleh penyelaras 1Bestari berpandukan item yang terdapat dalam senarai semak kompetensi kemahiran.

\section{DAPATAN KAJIAN}

Frekuensi dan peratusan daripada borang soal selidik dan senarai kompetensi kemahiran dianalisis secara deskriptif. Manakala untuk mendapatkan min dan aras signifikan bagi markah soalan pengujian pula dianalisis secara interfensi menggunakan ujian-t. 


\section{Dapatan Soalan Pengujian}

Jadual 1: Perbezaan Min antara markah ujian pra dan ujian pasca bagi kumpulan kawalan dan rawatan.

\begin{tabular}{lllcc}
\hline & & N & Min & Sisihan Piawai \\
\hline \multirow{2}{*}{ Pencapaian } & Kaedah Tradisional & 30 & 14.333 & .63 \\
& Frog VLE & 30 & 15.267 & .76 \\
\hline
\end{tabular}

Jadual 1 menunjukkan jadual statistik berkumpulan yang diperolehi daripada hasil ujian independent $t$-test yang dijalankan. Jadual di atas menunjukkan daripada $n=60$ sampel yang terlibat, seramai $n=30$ sampel pelajar dari kumpulan kawalan yang menggunakan kaedah tradisional dan seramai $n=30$ sampel pelajar dari kumpulan rawatan yang menggunakan kaedah Frog VLE. Jika dilihat dari segi nilai min pencapaian yang diperolehi, bagi kumpulan kawalan purata nilai (min $=14.33$, sisihan piawai=0.63) dan nilai min pencapaian yang diperolehi, bagi kumpulan rawatan purata nilai (min=15.27, sisihan piawai=0.76). Hasil dapatan menunjukkan kedua-dua kaedah mempunyai perbezaan nilai min pencapaian yang ketara di mana pembelajaran menggunakan kaedah Frog VLE lebih berkesan terhadap pemahaman pelajar dan pencapaian mereka di dalam bilik darjah.

Ujian-t telah dijalankan kepada data yang diperoleh menganalisis data ini bagi menganalisis perbezaan antara kaedah Frog VLE dan kaedah tradisional. Hasil dapatan kajian adalah seperti yang ditunjukkan dalam Jadual 2. Hasil dapatan data digunakan untuk menganalisis perbezaan antara kaedah Frog VLE dan kaedah tradisional. Ujian statistik yang digunakan adalah Ujian-t.

Jadual 2: Kaedah Frog VLE dan kaedah tradisional.

\begin{tabular}{|c|c|c|c|c|c|c|c|}
\hline \multirow[t]{3}{*}{$\mathbf{N}$} & \multicolumn{2}{|c|}{ Kumpulan Rawatan } & \multicolumn{2}{|c|}{ Kumpulan Kawalan } & \multirow{3}{*}{$\begin{array}{l}\text { Beza } \\
\text { Min }\end{array}$} & \multirow{3}{*}{ Nilai t } & \multirow{3}{*}{ Nilai signifikan } \\
\hline & Min & Sisihan & Min & Sisihan & & & \\
\hline & & Piawai & & Piawai & & & \\
\hline 60 & 15.27 & 0.76 & 14.33 & 0.63 & .94 & -1.966 & .044 \\
\hline
\end{tabular}

Nota, N=bilangan

Berdasarkan Jadual 2 yang menunjukkan analisis ujian-t, didapati nilai $t=-1.966, \mathrm{p}=0.044$ ( $\mathrm{p}<0.05$ ). Maka, hasil dapatan dapat dirumuskan bahawa terdapat perbezaan signifikan min pencapaian pelajar yang menggunakan kaedah Frog VLE dengan kaedah tradisional bagi mata pelajaran Matematik dalam kalangan pelajar Tahun 2. 


\section{Dapatan Tahap Kepuasan Menggunakan Frog VLE}

Soalan yang berkaitan dengan tahap kepuasan menggunakan Frog VLE dari segi kepuasan terhadap kesesuaian bahan yang disediakan, kepuasan terhadap aspek mesra pengguna aplikasi Frog VLE dan kepuasan terhadap reka bentuk.

Jadual 3: Pembahagian skor min mengikut skala.

\begin{tabular}{cc}
\hline Skor Min & Tahap \\
\hline 1 hingga 1.49 & Sangat tidak setuju \\
1.5 hingga 2.49 & Tidak setuju \\
2.5 hingga 3.49 & Tidak pasti \\
3.5 hingga 4.49 & Setuju \\
4.5 hingga 5.00 & Sangat setuju \\
\hline
\end{tabular}

Analisis Deskriptif Tahap Kepuasan Terhadap Kesesuaian Bahan Yang Disediakan

Hasil analisis deskriptif tahap kepuasan terhadap kesesuaian bahan yang disediakan dalam Frog VLE mendapati tahap kepuasan terhadap kesesuaian bahan yang disediakan dalam Frog VLE berada pada tahap setuju, iaitu 4.42. Ini menunjukkan pelajar mempunyai kepuasan pada tahap setuju. Didapati item bahan pembelajaran dalam aplikasi Frog VLE menarik mencatat skor min yang tertinggi, iaitu 4.67 yang menunjukkan pelajar sangat setuju. Manakala item bahan Frog VLE mudah difahami menunjukkan skor paling rendah, iaitu 4.20 di mana pelajar hanya setuju dengannya.

\section{Analisis Deskriptif Tahap Kepuasan Terhadap Aspek Mesra Pengguna Aplikasi Frog VLE $(N=30)$}

Keputusan analisis statistik menunjukkan min bagi tahap kepuasan pelajar terhadap aspek mesra pengguna aplikasi Frog VLE adalah 3.65, dan berada pada tahap setuju. Ini menunjukkan pelajar setuju dengan aspek mesra pengguna aplikasi Frog VLE. Hasil analisis mendapati, skor min bagi item elemen multimedia dalam Frog VLE mudah digunakan (video, audio, teks, grafik) mendapat skor paling tinggi (min=4.17) iaitu pelajar setuju, manakala skor min bagi item Frog VLE dapat memuat turun/memuat naik (download/upload) bahan dengan baik dan pantas, mendapat skor min paling rendah $(\mathrm{min}=3.27)$ menunjukkan pelajar berada pada tahap tidak pasti. Nilai min keseluruhan bagi tahap kepuasan terhadap aspek mesra pengguna aplikasi Frog VLE mendapati tahap kepuasan terhadap aspek mesra pengguna aplikasi Frog VLE berada pada tahap setuju, iaitu 3.65. 
Hasil analisis deskriptif tahap kepuasan terhadap reka bentuk Frog VLE mendapati tahap kepuasan terhadap reka bentuk Frog VLE berada pada tahap setuju, iaitu 4.11. Ini menunjukkan pelajar mempunyai kepuasan pada tahap setuju. Didapati item grafik yang digunakan membuatkan Frog VLE kelihatan menarik mencatat skor min yang tertinggi, iaitu 4.67 yang menunjukkan pelajar sangat setuju. Manakala item saiz tulisan yang digunakan membuatkan Frog VLE kelihatan menarik menunjukkan skor paling rendah, iaitu 4.20 di mana pelajar hanya setuju dengannya. Dapatan keseluruhan menunjukkan kesemua item dalam soal selidik menunjukkan pelajar berpuas dengan item yang disenaraikan dalam borang soal selidik.

\section{Dapatan Tahap Kemahiran Menggunakan Frog VLE}

Setelah data Senarai Semak Kompetensi Kemahiran pelajar terhadap penggunaan Frog VLE dianalisis, didapati ramai pelajar memiliki tahap kompetensi yang sederhana dalam membina dashboard dan site, Widget Media Widget Media Widget Text.Widget Quiz, Widget Link, Widget File Drop, Widget Wall dan Widget Poll. Maka, Senarai Semak Kompetensi Kemahiran Pelajar Terhadap Penggunaan Frog VLE, didapati majoriti pelajar memerlukan bimbingan guru mereka dalam menggunakan segala widget dan fungsi pada laman pembelajaran maya Frog VLE yang berkenaan berpandukan item yang terdapat dalam senarai semak kompetensi kemahiran.

\section{KESIMPULAN}

Sebagai rumusan kepada hasil dapatan kajian yang diperoleh daripada 60 orang responden perkara yang dapat disimpulkan berdasarkan kajian ini adalah ke semua tiga persoalan kajian telah dijawab. Antaranya adalah:

1. Terdapat perbezaan signifikan min pencapaian pelajar yang menggunakan kaedah Frog VLE berbanding kaedah tradisional bagi mata pelajaran Matematik dalam kalangan pelajar Tahun 2 ;

2. Tahap kepuasan pelajar Tahun 2 menggunakan kaedah Frog VLE adalah tinggi; dan

3. Tahap kemahiran pelajar Tahun 2 menggunakan kaedah Frog VLE adalah sederhana di mana pelajar memerlukan bimbingan guru.

\section{PENGHARGAAN}

Penulis ingin mengucapkan terima kasih dan sekalung penghargaan kepada Universiti Pendidikan Sultan Idris dan guru serta murid di Sekolah Jenis Kebangsaan Tamil Mahathma Gandhi Kalasalai yang menjayakan penyelidikan ini dan tidak dapat disempurnakan tanpa kerjasama yang diberikan oleh semua pihak. 


\section{RUJUKAN}

Hassan, J. B. \& Chung, Y. W. (2010). Keupayaan dan Kelemahan Menyelesaikan Masalah Matematik dalam Kalangan Pelajar Tingkatan Lima. Universiti Teknologi Malaysia.

Ida Norini Mahamad Tajudin. (2013). Kajian Tinjauan Mengenai Keberkesanan Penggunaan Konsep Frog VLE di Kalangan Pelajar SK Haji Mahmud Chemor Perak, Tanjung Malim: Universiti Pendidikan Sultan Idris.

Hassan, J. B. \& Chung, Y. W. (2010). Keupayaan dan Kelemahan Menyelesaikan Masalah Matematik dalam Kalangan Pelajar Tingkatan Lima. Universiti Teknologi Malaysia.

Mohamad Azrien, Mohamed Adnan, Sharifah Sariah, Syed Hassan. (2014). A Framework for Online Instructions in Learning Arabic as a Foreign Language via Learing Management System, 4th International Conference and Exhibition on Islamic Education (ICIEd 2014), 19-24.

Norazilawati Abdullah, Noraini Mohamed Noh, Nik Azmah Nik Yusoff, Rosnidar Mansor. (2013). Aplikasi Persekitaran Pengajaran Maya (Frog-VLE) dalam Kalangan Guru Sains. Prosiding 7th International Malaysian Education Technology Convention (IMETC), 16-18 September.

Nurul Farhana Junus. (2013). Cabaran dalam Mengimplementasi Virtual Learning Environment (VLE) Frog dalam Pengajaran dan Pembelajaran oleh Guru di Sekolah-Sekolah di Malaysia, (Unpublished Masters Project), UniversitiTeknologi Malaysia

Nurul Juzailah Jemain. (2013). Faktor-faktor Mempengaruhi VLE Frog Dalam Kalangan Guru Di Sekolah Menengah Kertas Projek. Fakulti Pendidikan, Universiti Pendidikan Sultan Idris

Shahfiezul Shahaimi, Fariza Khalid (2015). Persekitaran Pembelajaran Maya Frog (VLE-FROG) Di Sekolah-Sekolah Di Malaysia: Pelaksanaan Dan Cabaran, Prosiding Seminar Kebangsaan Pendidikan Negara Kali Ke-5, (Disember), 16-17

Siti Hashidah, Mohd Nasir, Halimah \& Harun. (2015). Penggunaan Persekitaran Pembelajaran Maya Frog (FROG VLE) dalam Pembelajaran Mata Pelajaran Perdagangan, Seminar Penyelidikan Pendidikan Kebangsaan (SPPK 2015), 361-731. 